\title{
Zoster sine herpete: a disease that ophthalmologists should be aware of
}

\author{
Haya H Al-Ani and Rachael L Niederer \\ Department of Ophthalmology, Greenlane Clinical Centre, Auckland District Health Board, Auckland, New Zealand
}

Received August 24, 2020, Accepted August 26, 2020

Handling Editor: Kyung Hoon Kim

Correspondence

Haya Al-Ani

Department of Ophthalmology, Auckland District Health Board, 214 Green Lane West, Greenlane Clinical Centre, Epsom, Auckland 1051, New Zealand Tel: +64-9-3670000, Fax: +64-9-3677173, E-mail: hayaa@adhb.govt.nz

\section{TO THE EDITOR}

We read with great interest the review by Zhou et al. [1] in the article "Zoster sine herpete: a review". Herpes zoster ophthalmicus is a well-known consequence of varicella zoster virus (VZV) reactivation, occurring in $10-20 \%$ of herpes zoster cases, and may cause potentially sightthreatening complications anywhere from the anterior segment through to the optic nerve, retina, and central nervous system [2]. Although less reported in the literature, zoster sine herpete (ZSH) also presents with intraocular manifestations which, if misdiagnosed and left untreated, can result in adverse visual outcomes.

As mentioned by Zhou et al., corneal involvement may occur in the form of keratitis $[1,3]$. Although there is no classic ophthalmic presentation, it appears in both the literature and anecdotally that the most common case is a raised intraocular pressure associated with anterior uveitis [4-6]. Slit lamp examination may show inflammatory deposits on the posterior corneal surface, anterior chamber inflammation, trabecular meshwork pigmentation, iris atrophy, and/or adhesions between the iris and the lens (posterior synechiae), causing a distorted pupil. Inflam- mation may persist as chronic anterior uveitis, which can lead to uveitic glaucoma, a potentially sight-threatening complication [5]. In rare cases, acute anterior uveitis with a hyphaema has been the clinical presentation of ZSH $[7,8]$.

We acknowledge that the key to diagnosing ZSH is having a high level of suspicion and subsequent laboratory testing. Polymerase chain reaction (PCR) testing for VZV DNA in the aqueous humour is essential for definitive diagnosis and subsequent management with antiviral therapy. A higher viral load in aqueous sampling is significantly associated with uveitic complications of iris atrophy and pupil distortion [4], which suggests that ongoing VZV replication will perpetuate inflammation and increases the risk of associated complications. This highlights the importance of early initiation and appropriate duration of antiviral therapy to minimise this risk.

Limited published evidence on ZSH in general, and even more so in an ophthalmology context, means that there are no established guidelines on recommended management and therapy. Our recommendation is that ZSH should be considered in patients presenting with anterior uveitis with elevated intraocular pressure, but particularly in those with slit lamp findings of iris atrophy, or pupil dis- (c) This is an open-access article distributed under the terms of the Creative Commons Attribution Non-Commercial License (http://creativecommons.org/licenses/by-nc/4.0/), which permits unrestricted non-commercial use, distribution, and reproduction in any medium, provided the original work is properly cited.

(c) The Korean Pain Society, 2020
Author contributions: Haya H Al-Ani: Writing/manuscript preparation; Rachael L Niederer: Supervision. 
tortion. Performing an anterior chamber tap for VZV PCR is necessary to make a definitive diagnosis, but treatment with antiviral therapy in cases of high clinical suspicion should not be delayed if PCR testing is unable to be performed.

\section{CONFLICT OF INTEREST}

No potential conflict of interest relevant to this article was reported.

\section{FUNDING}

No funding to declare.

\section{ORCID}

Haya H Al-Ani, https://orcid.org/0000-0002-1813-7625

Rachael L Niederer, https://orcid.org/0000-0002-4311-859X

\section{REFERENCES}

1. Zhou J, Li J, Ma L, Cao S. Zoster sine herpete: a review. Ko- rean J Pain 2020; 33: 208-15.

2. Liesegang TJ. Herpes zoster ophthalmicus natural history, risk factors, clinical presentation, and morbidity. Ophthalmology 2008; 115(2 Suppl): S3-12.

3. Silverstein BE, Chandler D, Neger R, Margolis TP. Disciform keratitis: a case of herpes zoster sine herpete. Am J Ophthalmol 1997; 123: 254-5.

4. Kido S, Sugita S, Horie S, Miyanaga M, Miyata K, Shimizu N, et al. Association of varicella zoster virus load in the aqueous humor with clinical manifestations of anterior uveitis in herpes zoster ophthalmicus and zoster sine herpete. $\mathrm{Br} \mathrm{J}$ Ophthalmol 2008; 92: 505-8.

5. Nakamura M, Tanabe M, Yamada Y, Azumi A. Zoster sine herpete with bilateral ocular involvement. Am J Ophthalmol 2000; 129: 809-10.

6. Schwab IR. Herpes zoster sine herpete. A potential cause of iridoplegic granulomatous iridocyclitis. Ophthalmology 1997; 104: 1421-5.

7. Okunuki Y, Sakai J, Kezuka T, Goto H. A case of herpes zoster uveitis with severe hyphema. BMC Ophthalmol 2014; 14: 74.

8. Hayasaka S, Watanabe M, Yamamoto Y, Noda S, Sekimoto M, Setogawa T. Herpes zoster ophthalmicus complicated by hyphema and hemorrhagic glaucoma. Ophthalmologica 1988; 196: 185-7. 